\title{
ASO Author Reflections: Does a Diagnosis of Ulcerative Colitis Affect Outcome in Colorectal Cancer?
}

\author{
Viviane Lin, $\mathrm{MD}^{1,2}$ (1) , Tina Fransgaard, $\mathrm{MD}, \mathrm{PhD}^{1}$, and Ismail Gögenur, DMSc ${ }^{1}$ \\ ${ }^{1}$ Center for Surgical Science, Department of Surgery, Zealand University Hospital, Køge, Denmark; ${ }^{2}$ Department of \\ Surgery, Nordsjællands Hospital Hillerød, Hillerød, Denmark
}

\section{PAST}

Patients experiencing ulcerative colitis are shown to be at higher risk for the development of colorectal cancer due to chronic inflammation, and some previous studies have shown worse survival for these patients than for those with sporadic colorectal cancer. ${ }^{1}$ With incidences of inflammatory bowel disease (IBD) rising in developed and developing countries, ${ }^{2}$ and with the rising incidence of cancer in the younger population, ${ }^{3}$ it is relevant to look further into the long-term oncologic outcome for this growing patient population whose carcinogenesis differs from the classic adenoma-carcinoma sequence. ${ }^{4}$

\section{PRESENT}

A nationwide observational study investigated patients undergoing curative-intent surgery for colorectal cancer with and without ulcerative colitis using the Danish Colorectal Cancer Group (DCCG) database. ${ }^{5}$ The study analyzed all-cause mortality and estimated disease-free survival (DFS) as well as recurrence-free survival (RFS) in the study's patient population. In addition, a meta-analysis of the existing literature was performed, including the authors' own findings. No significant association could be demonstrated between preexisting IBD and DFS or RFS after surgery and those of a population that had no IBD.

(C) Society of Surgical Oncology 2021

First Received: 10 August 2021

Accepted: 10 August 2021;

Published Online: 25 August 2021

V. Lin, MD

e-mail:vial@regionsjaelland.dk

\section{FUTURE}

This study showed no association between oncologic survival metrics and preexisting IBD. This does not rule out the impact of specific drug treatments or phenotypes related to IBD on long-term oncologic outcomes, and this should be explored in the future.

DISCLOSURE There are no conflicts of interest.

\section{REFERENCES}

1. Olén O, Erichsen R, Sachs MC, et al. Colorectal cancer in ulcerative colitis: a Scandinavian population-based cohort study. Lancet. 2020;395:123-31. https://doi.org/10.1016/S0140-6736(19 32545-0.

2. Mak WY, Zhao M, Ng SC, Burisch J. The epidemiology of inflammatory bowel disease: east meets West. $J$ Gastroenterol Hepatol. 2020;35:380-9. https://doi.org/10.1111/jgh.14872.

3. Bailey CE, Hu C-Y, You YN, et al. Increasing disparities in the age-related incidences of colon and rectal cancers in the United States, 1975-2010. JAMA Surg. 2015;150:17-22. https://doi.org/ 10.1001/jamasurg.2014.1756.

4. Yaeger R, Shah MA, Miller VA, et al. Genomic alterations observed in colitis-associated cancers are distinct from those found in sporadic colorectal cancers and vary by type of inflammatory bowel disease. Gastroenterology. 2016;151:278-87.e6. https://doi. org/10.1053/j.gastro.2016.04.001.

5. Lin V, Lohse R, Madsen MT, Fransgaard T, Remzi F, Gögenur I. Long-term outcomes after colorectal surgery in patients with ulcerative colitis-associated colorectal cancer versus sporadic colorectal cancer. Ann Surg Oncol.

Publisher's Note Springer Nature remains neutral with regard to jurisdictional claims in published maps and institutional affiliations. 